ITAS-A-Rad and PGA (72\%, $\kappa: 0.50)$ and also Kerr et al. criteria (82\%, $\kappa: 0.56)$ was found to be moderate. Interestingly, when only USG (ITAS-A-USG) or only MRA (ITAS-A-MRA) was used, the agreement with PGA was remained unchanged (73\%, к: 0.45 and $76 \%, \kappa: 0.52$, respectively).

When responsiveness to change of ITAS-A-Rad score was evaluated by serial visits of patients, it was found that the mean value of the score was discriminative for activity according to PGA in 9 of 11 visits (Figure 1).

Conclusions: The results of this study suggest that ITAS-A-Rad may be used to be a valuable follow-up parameter in the assessment of disease activity.

Disclosure of Interest: None declared

DOI: 10.1136/annrheumdis-2017-eular.6271

\section{THU0315 CENTRAL NERVOUS SYSTEM INVOLVEMENT IN PATIENTS WITH GRANULOMATOSIS WITH POLYANGIITIS: A SINGLE CENTER EXPERIENCE}

G.E. Fragoulis ${ }^{1}$, S. Lionaki ${ }^{2}$, A. Venetsanopoulou ${ }^{1}$, P.G. Vlachoyiannopoulos ${ }^{1}$, H.M. Moutsopoulos ${ }^{1}$, A.G. Tzioufas ${ }^{1} .{ }^{1}$ Pathophysiology Department;

${ }^{2}$ Nephrology Department, University of Athens, School of Medicine, Athens, Greece

Background: Peripheral nerve involvement is relatively frequently encountered in patients with granulomatosis with polyangiitis (GPA). Central nervous system (CNS) manifestations are reported to occur in about $10 \%$ of GPA patients.

Objectives: We aimed to estimate the prevalence of CNS involvement in Greek patients with GPA, describe the related clinical characteristics, and identify possible predicting factors for its occurrence. We also compared the clinical picture and long term outcomes of GPA patients with and without CNS involvement.

Methods: The medical charts of all patients with ANCA-associated and biopsy proven small vessel vasculitis (AAV), diagnosed in our hospital between 19952015, were retrospectively reviewed and GPA patients with CNS involvement were identified. Demographics, serological and clinical features, at the time of AAV diagnosis, of CNS involvement and during the follow-up time, were recorded. Comparisons of disease characteristics and outcomes, including patient survival, relapse rate and treatment-related adverse events, were performed between GPA patients with and without CNS involvement.

Results: 77 patients with GPA were identified in our AAV registry. Of these, nine (11.7\%) developed CNS manifestations, either at clinical presentation (33.3\%) or during the follow-up (66.7\%). At the time of CNS involvement, all patients were characterized by increased acute phase reactants and all but one patients had vasculitic manifestations in several other organs/systems and increased titers of ANCA. CNS symptomatology included: sensor and/or sensorimotor symptomatology (33.3\%), severe headache and hearing loss (33.3\%), delirium and seizures $(22.2 \%)$, diplopia $(11.1 \%)$ and cerebellar symptoms $(11.1 \%)$. Findings from MRI were: cerebral ischemic lesions (55.6\%), focal dural thickening with enhancement $(22.2 \%)$, orbital mass formation $(11.1 \%)$ and mastoiditis causing facial nerve palsy bilaterally (11.1\%). Patients with CNS involvement, compared to those without, at initial AAV diagnosis, experienced vasculitic manifestations of the ENT system more frequently $(77.8 \%$ versus $25.4 \%, p=0.004)$ and they had a lower disease activity, as assessed by the BVAS score, while during the overall course of the disease experienced lung vasculitis less frequently $(44.4 \%$ vs. $79.4 \%, p=0.02$ ). Comparisons between GPA patients with and without CNS manifestations did not reveal any differences in long-term outcomes including relapse rate rate/100 person-months, $(95 \% \mathrm{Cl})[1.812(0.920-3.229)$ Vs 1.033 , $(0.757-1.378)$, respectively] $(p=0.171)$, survival (Mantel-Cox test, $p=0.244)$ and treatment-related adverse events

Conclusions: CNS involvement was recorded in $11.7 \%$ of our GPA patients, either during the initial phase or as a late disease sequela. ENT involvement and low BVAS score at disease onset were more common in GPA patients with CNS manifestations. Based on our results, CNS involvement did not affect the long term outcomes of GPA patients.

Disclosure of Interest: None declared

DOI: 10.1136/annrheumdis-2017-eular.6574

\section{THU0316 EPIDEMIOLOGY OF TAKAYASU ARTERITIS IN NORTHERN ITALY}

G. Restuccia ${ }^{1}$, L. Boiardi ${ }^{1}$, P. Macchioni ${ }^{1}$, M. Catanoso ${ }^{1}$, P. Mancuso ${ }^{2}$ C. Salvarani ${ }^{1} .{ }^{1}$ Rheumatology, Arcispedale S Maria Nuova; ${ }^{2}$ Servizio interaziendale di epidemiologia, Azienda unità sanitaria locale, Reggio Emilia e Arcispedale S Maria Nuova, Reggio Emilia, Italy

Background: Takayasu arteritis (TAK) is a large vessel vasculitis of unknown etiology, predominantly affecting the aorta and/or its major branches and occurring before the age of 40 years. TAK has been described worldwide with an annual incidence in Europe ranging from 0.4 to $1.3 / 1.000 .000$. TAK is more common in female. In the largest study from Japan, the female to male ratio was eight to one. In a recent Swedish epidemiologic study no male were identified. There are no epidemiological studies regarding Takayasu arteritis in Italian population.

Objectives: To investigate the epidemiology of Takayasu arteritis in a Northern Italy area.

Methods: All patients with incident TAK diagnosed between 1997 and 2015 living in the Reggio Emilia area were identified by capture and re-capture checking at computerized discharge diagnosis codes (ICD10) and at outpatients databases from rheumatology, internal medicine, surgery, pathology, imaging departments of Reggio Emilia Hospital and by examining the Reggio Emilia district database for rare diseases. The Reggio Emilia population is predominantly of Caucasian origin $(92.5 \%$ ) with a yearly increase in general population of $0.5 \%$ (from 438.588 inhabitants in 1997 to 533.827 in 2015).

Results: There were 5 women satisfyng ACR 1990 criteria for TAK diagnosis during the 18 years study period. The overall age and sex-adjusted 18 years incidence per 100.000 persons aged $<40$ years was 2.2. (95\% Cl:0.71 to 5.09 ). The overall age-and sex-adjusted 20 years incidence per 100,000 women aged $<40$ years was 4.5 . (95\% Cl:1.46 to 10.48). Median age at disease onset was $36 \mathrm{y}$ and at diagnosis was 39 years. The prevalence of TAK in the general population on December 312015 was 0.9 (95\% Cl: 0.31 to 2.19) while in female population aged $<40$ years was $4.4(95 \% \mathrm{Cl} 1.47$ to 10.54$)$. All patients are still alive on December 312015.

Conclusions: As observed in other epidemiological studies, TAK is a rare disease also in Northern Italy with a large prevalence of female.

Disclosure of Interest: None declared

DOI: 10.1136/annrheumdis-2017-eular.5477

\section{THU0317 CARDIOVASCULAR RISK FACTORS AND COMORBID DISEASES IN TAKAYASU ARTERITIS}

H. Masyan ${ }^{1}$, N.S. Esatoglu ${ }^{2}$, A.M. Celik ${ }^{1}$, V. Hamuryudan ${ }^{2}$, H. YazıcI ${ }^{2}$, E. Seyahi ${ }^{2} .{ }^{1}$ Department of internal medicine; ${ }^{2}$ Department of internal medicine, Division of Rheumatology, Cerrahpasa medical faculty, Istanbul, Turkey

Objectives: Cardiovascular complications are the main causes of morbidity and mortality in the course of Takayasu arteritis (TA).In addition to the occlusive vasculitis, hypertension and accelerated atherosclerosis are possibly other factors playing role in the ethiopathogenesis of these complications.Although,strict management of traditional cardiovascular risk factors is advocated to diminish the effect of cardiovascular complications, we still do not know whether traditional risk factors and other comorbid conditions are increased or operative. In this study we looked at the frequency of traditional atherosclerotic risk factors and comorbid conditions among patients with TA and suitable diseased and healthy controls.

Methods: We studied 88 (77F,11M) consecutive TA patients and 71 (66F,5M) SLE patients,between May and November 2016.In addition,age and gender matched, $96(80 \mathrm{~F}, 16 \mathrm{M})$ healthy controls were included.Study participants were interviewed with the help of a standardized questionnaire that assess the presence or absence of traditional atherosclerotic risk factors and several comorbid conditions according to the Charlson comorbidity index.Additionally,Framingham coronary heart disease risk score was calculated.

Results: Smoking was more frequent among the healthy controls,whereas hypertension and family history of cardiovascular diseases were more common among TA patients.Patients with SLE were found to have less hyperlipidemia.The Framingham risk scores did not differ among the groups.Pericardial/pleural and renal diseases were more frequently observed in SLE patients,whereas cardiovascular diseases and chronic lung diseases were more common in TA patients. Inflammatory bowel diseases were only observed in TA patients.

\begin{tabular}{lcccc}
\hline & $\begin{array}{c}\text { Takayasu arteritis } \\
(\mathrm{n}=88 ; \\
77 \mathrm{~F} / 11 \mathrm{M})\end{array}$ & $\begin{array}{c}\mathrm{SLE} \\
(\mathrm{n}=71 ; \\
66 \mathrm{~F} / 5 \mathrm{M})\end{array}$ & $\begin{array}{c}\text { Healthy controls } \\
(\mathrm{n}=96 ; \\
80 \mathrm{~F} / 16 \mathrm{M})\end{array}$ & P value \\
\hline Age, mean $\pm \mathrm{SD}$ & $44 \pm 12$ & $42 \pm 12$ & $45 \pm 11$ & $\mathrm{NS}$ \\
Age at disease onset, mean $\pm \mathrm{SD}$ & $31 \pm 12$ & $29 \pm 11$ & - & $\mathrm{NS}$ \\
Smoking (current and past), $\mathrm{n}(\%)$ & $27(31)$ & $30(42)$ & $47(49)$ & $<0.05$ \\
Hyperlipidemia, $\mathrm{n}(\%)$ & $32(44)$ & $15(25)$ & $41(48)$ & 0.018 \\
Hypertension, $\mathrm{n}(\%)$ & $47(53)$ & $23(32)$ & $22(23)$ & $<0.01$ \\
Diabetes mellitus, $\mathrm{n}(\%)$ & $8(9)$ & $6(7)$ & $15(16)$ & $\mathrm{NS}$ \\
Median [IQR] Framingham risk score & $3[1-9]$ & $3[1-5]$ & $3[2-7]$ & $\mathrm{NS}$ \\
Familial history of cardiovascular & & & & \\
$\quad$ diseases, $\mathrm{n}(\%)$ & $41(47)$ & $15(21)$ & $22(23)$ & $<0.01$ \\
Cardiovascular diseases, $\mathrm{n}(\%)$ & $47(53)$ & $13(18)$ & $1(1)$ & $<0.01$ \\
Valvular heart disease, $\mathrm{n}(\%)$ & $34(39)$ & $12(17)$ & $7(7)$ & $<0.01$ \\
Chronic pulmonary diseases, $\mathrm{n}(\%)$ & $11(13)$ & $1(2)$ & $5(6)$ & $<0.05$ \\
Pleural/pericardial diseases, $\mathrm{n}(\%)$ & $7(8)$ & $14(20)$ & 0 & $<0.01$ \\
Renal diseases, $\mathrm{n}(\%)$ & $10(11)$ & $19(27)$ & $8(8)$ & $<0.05$ \\
Other accompanying rheumatologic & & & & \\
$\quad$ diseases and amyloidosis, $\mathrm{n}(\%)$ & $10(11)$ & $15(21)$ & $1(1)$ & $<0.01$ \\
Inflammatory bowel diseases, $\mathrm{n}(\%)$ & $9(11)$ & 0 & 0 & $<0.01$ \\
Inflammatory upper/lower back pain, & & & & \\
$\quad \mathrm{n}(\%)$ & $21(24)$ & $23(32)$ & $6(6)$ & $<0.01$ \\
Family history of rheumatologic & & & & \\
$\quad$ diseases, $\mathrm{n}(\%)$ & $26(30)$ & $25(35)$ & $4(4)$ & $<0.01$ \\
\hline
\end{tabular}

Conclusions: Traditional atherosclerotic risk factors are not increased in TA.Comorbidities in these patients are mainly due to the complications of vascular involvement. The frequency of inflammatory bowel diseases and inflammatory upper/lower back pain is substantially high and deserves further research. Moreover, the increased incidence of cardiovascular and rheumatologic diseases among the first-degree relatives of TA patients suggest that genetic mechanisms may play role in TA

Disclosure of Interest: None declared

DOI: 10.1136/annrheumdis-2017-eular.6280 